\title{
Cycloaddition of Tetramethyldisiloxane to Alkynes with $[\mathrm{Au}] / \mathrm{TiO}_{2}$
}

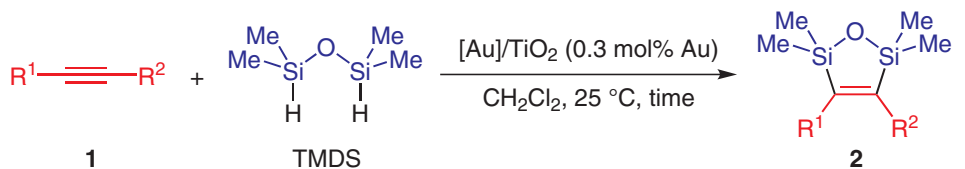

up to $99 \%, 22$ examples

Selected examples:

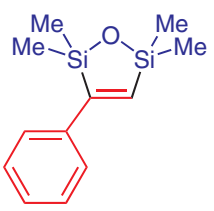

2a

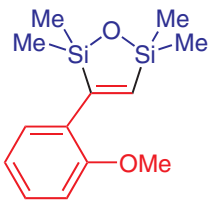

2b

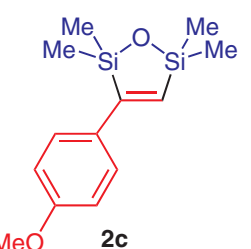

$40 \mathrm{~min}, 96 \%$ isolated yield)

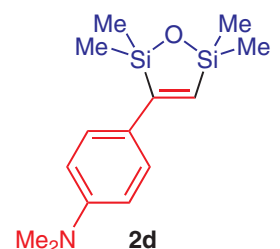

$40 \mathrm{~min}, 81 \%$ isolated yield)

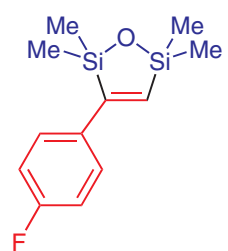

$2 e$

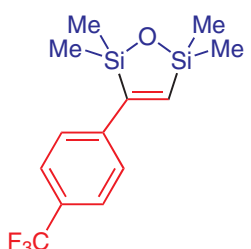

$2 f$

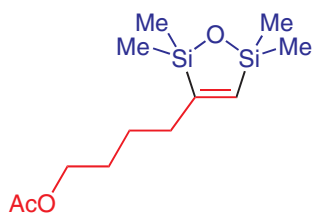

$2 \mathrm{~g}$

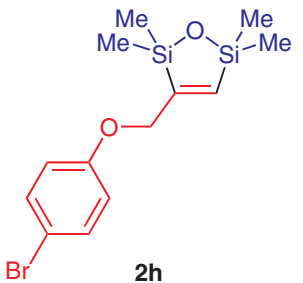

(20 $\mathrm{min}, 85 \%$ isolated yield) (20 $\mathrm{min}, 91 \%$ isolated yield) (30 $\mathrm{min}, 98 \%$ isolated yield)<smiles>C[Si]1(C)C=C([S+](C)(C)C)[Si](C)(C)O1</smiles>

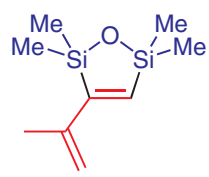

2j

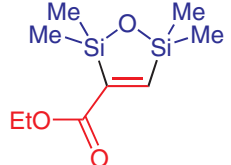

2k
30 min, $72 \%$ isolated yield)

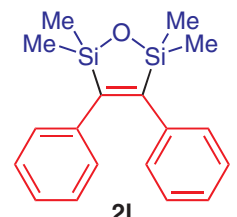

$(24 \mathrm{~h}, 88 \%$ isolated yield)

Proposed reaction pathway:

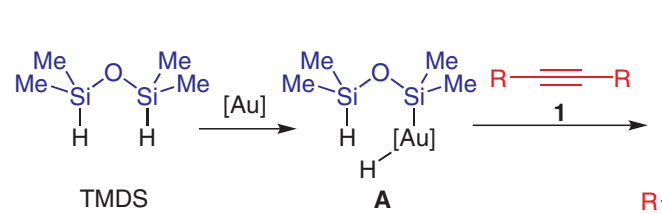

TMDS

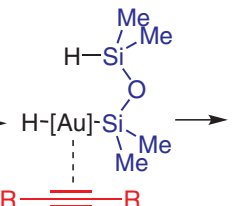

B

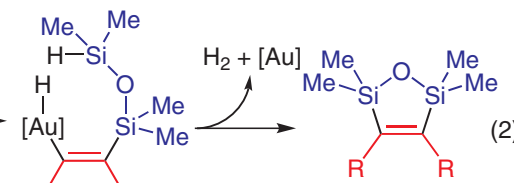

2
Key words

cycloaddition

1,1,3,3-tetramethyldisiloxane

alkynes

gold nanoparticles

titanium(IV) oxide

heterogeneous catalysis

SYNFACT
Significance: $\mathrm{TiO}_{2}$-supported gold nanoparticles $\left([\mathrm{Au}] / \mathrm{TiO}_{2}\right)$ catalyzed the oxidative cycloaddition of 1,1,3,3-tetramethyldisiloxane (TMDS) to alkynes $\mathbf{1}$ to give the corresponding cycloadducts 2 in up to $99 \%$ isolated yield (22 examples, eq. 1).

SYNFACTs Contributors: Yasuhiro Uozumi, Go Hamasaka

Synfacts 2011, 10,1137-1137 Published online: 20.09.2011

DoI: 10.1055/s-0030-1261087; Reg-No.: Y09811SF
Comment: The authors proposed a reaction pathway for the present oxidative cycloaddition as follows (eq. 2): (1) oxidative addition of TMDS to [Au] giving $\mathrm{H}$-[Au]- $\mathrm{Me}_{2} \mathrm{SiOSiHMe}_{2}(\mathbf{A})$; (2) insertion of alkynes 1 into the Si-Au bond forming gold adducts B; (3) intramolecular elimination of $\mathrm{H}_{2}$ and [Au] to give cycloadducts $\mathbf{2}$. 